\title{
mGlu5 Acts As a Switch for Opposing Forms of Synaptic Plasticity at Mossy Fiber-CA3 and Commissural Associational-CA3 Synapses
}

\author{
Hardy Hagena and Denise Manahan-Vaughan \\ Department of Neurophysiology, Medical Faculty, Ruhr University Bochum, 44780 Bochum, Germany
}

Within the hippocampus, different kinds of spatial experience determine the direction of change of synaptic weights. Synaptic plasticity resulting from such experience may enable memory encoding. The $\mathrm{CA} 3$ region is very striking in this regard: due to the distinct molecular properties of the mossy fiber (MF) and associational-commissural (AC) synapses, it is believed that they enable working memory and pattern completion. The question arises, however, as to how information reaching these synapses results in differentiated encoding. Given its crucial role in enabling persistent synaptic plasticity in other hippocampal subfields, we speculated that the metabotropic glutamate receptor mGlu5 may regulate information encoding at MF and AC synapses. Here, we show that antagonism of mGlu5 inhibits LTP, but not LTD at MF synapses of freely behaving adult rats. Conversely, mGlu5 antagonism prevents LTD but not LTP at AC-CA3 synapses. This suggests that, under conditions in which mGlu5 is activated, LTP may be preferentially induced at MF synapses, whereas LTD is favored at AC synapses. To assess this possibility, we applied $50 \mathrm{~Hz}$ stimulation that should generate postsynaptic activity that corresponds to $\theta_{\mathrm{m}}$, the activation threshold that lies between LTP and LTD. MGlu5 activation had no effect on AC responses but potentiated MF synapses. These data suggest that $\mathrm{mGlu} 5$ serves as a switch that alters signal-to-noise ratios during information encoding in the CA3 region. This mechanism supports highly tuned and differentiated information storage in CA3 synapses.

Key words: CA3; commissural-associational; hippocampus; in vivo; MPEP; pattern completion

\section{Introduction}

The pyramidal cells of the CA3 region receive projections from the dentate gyrus, which form the mossy fiber (MF)-CA3 synapses. Recurrent fibers arising from CA3 pyramidal cells give rise to the associational-commissural (AC)-CA3 synapses (Blackstad, 1956; Blackstad et al., 1970; Amaral, 1979). These two different CA3 inputs are believed to play a crucial role in spatial learning (Kesner and Warthen, 2010; Hagena and ManahanVaughan, 2011; Nakashiba et al., 2012; Neunuebel and Knierim, 2014). In the hippocampus, spatial experience drives changes in synaptic weights. Exposure to novel scenes or changes of substantial aspects of these scenes facilitates input-specific LTP in synapses of the hippocampal subfields (Kemp and ManahanVaughan, 2007), including the MF-CA3 and AC-CA3 synapses (Hagena and Manahan-Vaughan, 2011). In contrast, exploration of novel spatial content enables LTD (Kemp and ManahanVaughan, 2004, 2007, 2008; Goh and Manahan-Vaughan,

Received Aug. 15, 2014; revised Jan. 8, 2015; accepted Feb. 10, 2015.

Author contributions: D.M.-V. designed research; H.H. performed research;H.H. and D.M.-V. analyzed data; H.H. and D.M. - V. wrote the paper.

This work was funded by a German Research Foundation (Grant SFB874/B1 to D.M.V.V.). We thank Jens ColittiKlausnitzer for technical assistance and Silke Dirk and Nadine Kollosch for support in animal care.

The authors declare no competing financial interests.

Correspondence should be addressed to Denise Manahan-Vaughan, PhD, Department of Neurophysiology, Medical Faculty, Ruhr University Bochum, MA 4/150. Universitaetsstr. 150, 44780 Bochum, Germany. E-mail: denise.manahan-vaughan@rub.de.

DOI:10.1523/JNEUROSCI.3417-14.2015

Copyright $\odot 2015$ the authors $\quad 0270-6474 / 15 / 354999-08 \$ 15.00 / 0$ 2013c). The CA3 region is very striking in this regard: novel exploration of landmark objects results in MF-LTD, whereas novel exploration of discrete positional features of the environment enables AC-LTD (Hagena and Manahan-Vaughan, 2011).

The MF-CA3 synapse may enable hippocampus-dependent working memory and pattern completion (Hagena and ManahanVaughan, 2010; Kesner and Warthen, 2010; Nakashiba et al., 2012; Neunuebel and Knierim, 2014). The AC circuitry may support this kind of information processing, but the finding that both synapses express very persistent forms of synaptic plasticity (Hagena and Manahan-Vaughan, 2011) suggests that they subserve distinct roles in information encoding and storage. If information flow into CA3 (triggered, e.g., by novel spatial experience) resulted equipotently in LTP at MF and AC synapses, then the AC circuitry would be merely auxiliary to information storage in the MF synapses. However, different kinds of spatial content result in LTD that is exclusive to MF or AC synapses, suggesting that this is not the case.

The metabotropic glutamate receptor mGlu5 is intrinsically required for persistent forms of hippocampal synaptic plasticity (Naie et al., 2007; Bikbaev et al., 2008; Neyman and ManahanVaughan, 2008; Mukherjee and Manahan-Vaughan, 2013) and for hippocampus-dependent memory (Naie and ManahanVaughan, 2004; Goh and Manahan-Vaughan, 2013a). Here, we investigated whether unidirectional changes in synaptic efficacy at MF and AC synapses are elicited by pharmacological manipulations of this receptor as a strategy to assess to what extent MF and $\mathrm{AC}$ plasticity are complementary to one another. 
We observed that antagonism of mGlu5 selectively prevents MF-LTP but not MF-LTD. In contrast, mGlu5 antagonism prevents AC-LTD but not AC-LTP. We then tested effects on afferent stimulation in the range of $\theta_{\mathrm{m}}$ (Bienenstock et al., 1982; Dudek and Bear, 1993; Lujan et al., 1996; Kemp and Manahan-Vaughan, 2005) that is believed to generate postsynaptic activity that results in an equivalent activation of LTP-promoting mechanisms and LTD-promoting mechanisms such that no ostensible change in synaptic strength is evident. Strikingly, agonist activation of mGlu5 had no effect on AC synapses, but led to synaptic potentiation in MF synapses. Together, our data suggest that activation of mGlu5 promotes synaptic encoding in the form of LTP at MF synapses and can serve to strengthen LTD at AC synapses. We propose that this mechanism comprises an amplification of signal-to-noise ratios in CA3 neurons such that working memory and pattern completion at MF synapses are optimized and favored.

\section{Materials and Methods}

Animals. The present study was performed in accordance with the European Communities Council Directive of 22 September 2010 (2010/63/ $\mathrm{EU})$ for care of laboratory animals and after approval of the local government ethics committee. All efforts were made to minimize the number of animals used.

Electrophysiology. Seven- to 8-week old male Wistar rats (Charles River) were anesthetized (pentobarbital, $52 \mathrm{mg} / \mathrm{kg}$, i.p.) and underwent chronic implantation of hippocampal electrodes and a guide cannula, as described previously (Hagena and Manahan-Vaughan, 2011). Briefly, for MF-CA3 implantations, the recording electrode was placed above the CA3 pyramidal layer of the dorsal hippocampus $3.2 \mathrm{~mm}$ posterior to bregma and $2.2 \mathrm{~mm}$ lateral to midline. The bipolar stimulation electrode was implanted $3.5 \mathrm{~mm}$ posterior to bregma and $2.0 \mathrm{~mm}$ lateral to midline. For AC-CA3 implantations, the recording electrode was placed 3.1 $\mathrm{mm}$ posterior to bregma and $4.2 \mathrm{~mm}$ lateral to midline (Fig. 1). To verify the correct positions of the electrodes, simultaneous evoked test pulses were applied during the implantation procedure and postmortem histological analysis were performed (Bock, 1989; Manahan-Vaughan et al., 1998). Animals received a guide cannula in the ipsilateral hemisphere to enable injections into the lateral cerebral ventricle (i.c.v.) as described previously (Manahan-Vaughan, 1997). Experiments were commenced 7-10 d after surgery. During all experiments, the animals could move freely in the recording chamber $(40 \times 40 \times 50 \mathrm{~cm})$ and had ad libitum access to food and water. To allow the animals to acclimatize, they were transferred to the experiment room the day before the experiment took place.

Animals were stringently assessed to confirm that recordings were obtained from MF-CA3 synapses. The MF synapse is highly sensitive to agonist activation of group II mGluRs by $\left[2 S, 2^{\prime} \mathrm{R}, 3^{\prime} \mathrm{R}\right)-2-\left(2^{\prime}, 3^{\prime}-\right.$ dicarboxycyclopropyl)glycine (DCG-IV)], which selectively inhibits MF-EPSPs but not AC-EPSPs (Kamiya et al., 1996; Yeckel et al., 1999). Animals were excluded from the study when the fEPSP responses evoked in the stratum lucidum failed to show strong sensitivity (i.e., a reduction of test-pulse-evoked responses by $60 \%$ or greater) to DCG-IV (20 ng, i.c.v), as described in Hagena and Manahan-Vaughan (2010). These assessments were conducted in separate experiments in which at least $7 \mathrm{~d}$ had elapsed after the conclusion of key experiments with the respective animal. Before running these tests, the input-output curve and the
fEPSP profile of the animal was compared with responses evoked at the start of the study to ensure that the prior experience of the animal would not affect the outcome. In addition, experiments were conducted to verify that that NMDAR-dependent LTP was not evident in the MF synapses (as described in Hagena and Manahan-Vaughan, 2010). Here, $30 \mathrm{~min}$ before tetanization to induce LTP, the NMDAR antagonist D-AP5 (3.9 $\mu$ g, i.c.v) was applied to determine whether LTP was influenced by the antagonist. MF animals that showed an inadequate response to DCG-IV or exhibited LTP that was sensitive to D-AP5 were excluded from analysis. AC inputs were identified upon electrophysiological criteria (appearance of the analog trace that was obtained during the implantation of the electrodes), dependence of LTP and LTD on NMDA receptors (data not shown), and postmortem histological analysis. Here, AC animals that did not show NMDAR-dependent plasticity or that exhibited postmortem electrode misplacements were excluded from analysis.

For recordings from freely behaving animals, the headstage was connected to an amplifier and stimulator via a flexible cable with a swivel connector. Recordings were analyzed and stored on computer and the EEG was monitored throughout experiments. To evoke fEPSPs, a biphasic pulse was given with half-wave duration of $0.2 \mathrm{~ms}$. For recordings, the stimulation intensity was set to produce a fEPSP that was $40 \%$ of the maximal obtainable. The intensity was found on the basis of an inputoutput curve (maximal stimulation, $900 \mu \mathrm{A}$ ). Each recording consisted of an average of 5 consecutive pulses at $0.025 \mathrm{~Hz}$. To ensure stability of recordings, all animals were first tested in a baseline experiment in which test-pulse stimulation was applied over the same time period as subsequent plasticity experiments. To induce LTD, low-frequency stimulation (LFS) consisting of 900 pulses at $1 \mathrm{~Hz}$ were given with a stimulus intensity that yielded potentials, which were $70 \%$ of the maximal fEPSP observed during the input-output curve analysis. LTP was induced by high-frequency stimulation (HFS) of afferent fibers. This comprised of 4 bursts of 100 pulses at $100 \mathrm{~Hz}$ with a 5 min interburst interval. For the $10 \mathrm{~Hz}, 20 \mathrm{~Hz}$, and $50 \mathrm{~Hz}$ experiments, the stimulation consists of 450 pulses. Animals participating in LTP experiments had a minimum age of 12 weeks because we observed that application of HFS in younger animals causes epileptiform seizures.

Pharmacological treatment. The mGlu5 receptor antagonist 2-methyl6-(phenylethynyl) pyridine (MPEP; Biozol) specifically blocks mGlu5 but not mGlu1 receptors with an $\mathrm{IC}_{50}$ for mGlu5 receptors of $36 \mathrm{~nm}$ 

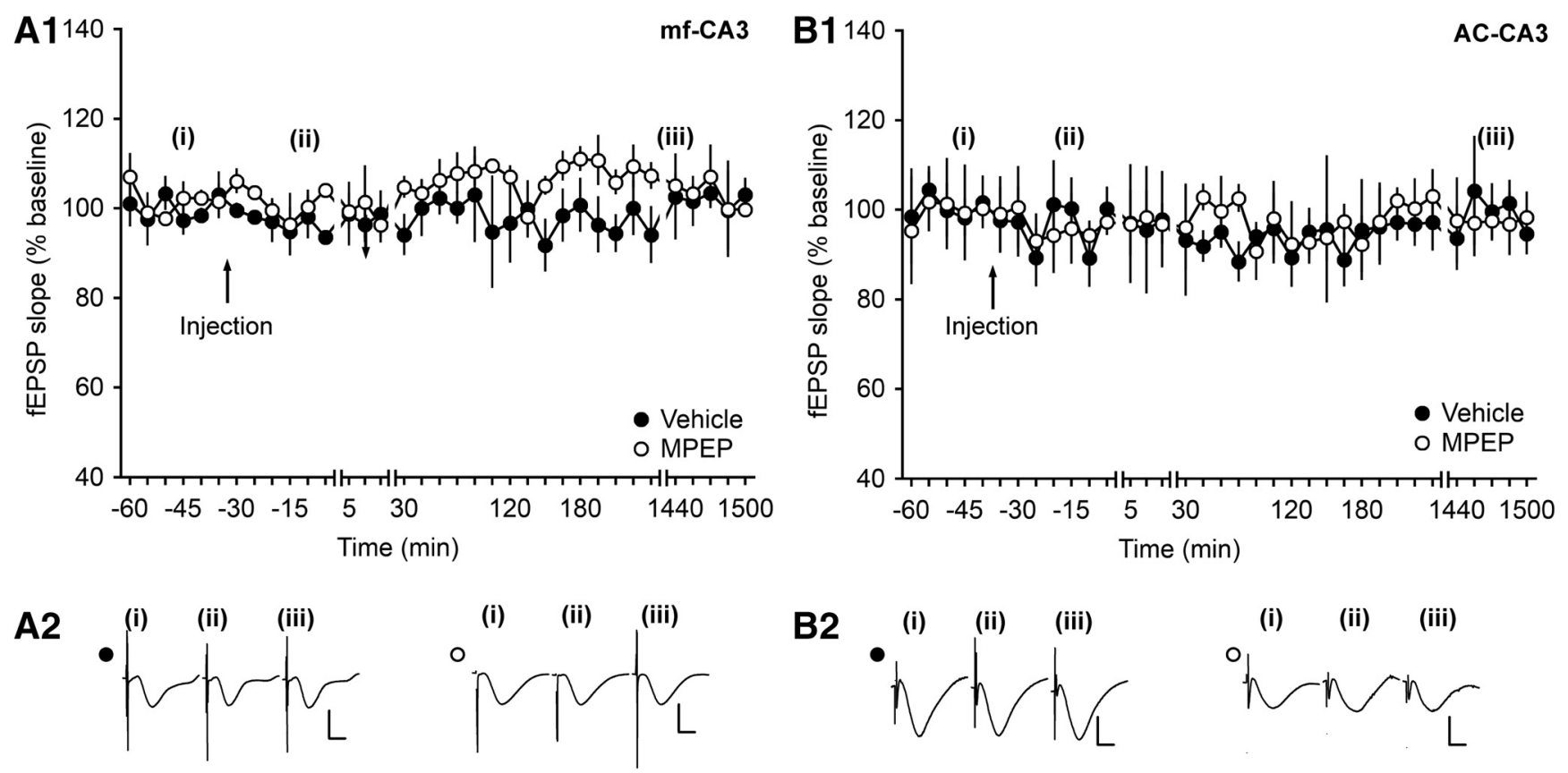

Figure 2. Injection of MPEP does not alter basal synaptic plasticity at MF-CA3 or AC-CA3 synapses. After injection of MPEP (1.8 $\mu \mathrm{g})$, fEPSPs evoked by test-pulse stimulation remained stable for $>24 \mathrm{~h}$ at MF-CA3 synapses (A1) and AC-CA3 synapses (B1) compared with vehicle-treated controls. Line breaks indicate change in time scale. $\mathbf{A 2}$, B2, Analogs represent responses evoked by test-pulse stimulation of MF-CA3 synapses (A2) or AC-CA3 synapses (B2) during a control experiment (closed circles) and during an MPEP experiment (open circles). The time points of recordings comprised preinjection (i), $5 \mathrm{~min}$ after injection (ii), and $24 \mathrm{~h}$ after injection (iii). Vertical scale bar, $2 \mathrm{mV}$; horizontal scale bar, $8 \mathrm{~ms}$.

(Gasparini et al., 1999). To treat animals with MPEP, $1.8 \mu \mathrm{g}$ was dissolved in $5 \mu \mathrm{l}$ of $0.9 \% \mathrm{NaCl}$. The specific mGlu 5 receptor agonist (R,S)-2chloro-5-hydroxyphenylglycine (CHPG) was dissolved in $1 \mathrm{~N} \mathrm{NaOH}$ and brought to the desired molarities with $0.9 \% \mathrm{NaCl}$. The dose given was 0.5 $\mu \mathrm{g}$. The group II mGlu receptor agonist DCG-IV (Tocris Cookson) was dissolved in isotonic saline $(0.9 \% \mathrm{NaCl})$ solution. The amount of DCG-IV that was used (20 ng) was chosen because it has no effect on evoked responses in the dentate gyrus (Klausnitzer and ManahanVaughan, 2008). The NMDAR antagonist D-(-)-2-amino-5-phosphonopentaoic acid (D-AP5; Tocris Cookson) was first dissolved in $5 \mu \mathrm{l}$ of $1 \mathrm{~N} \mathrm{NaOH}$ solution and then $0.9 \% \mathrm{NaCl}$ was added to make up a solution of $100 \mu \mathrm{l}$ volume. The injections were given $5 \mu$ l over a $5 \mathrm{~min}$ period via a Hamilton syringe. To assess whether the injected solution influences evoked responses, test pulses were given over a $24 \mathrm{~h}$ period. All injections were performed 30 min before stimulation except in the study in which we tested whether the residual LTD after MPEP injection was NMDA receptor dependent. Here, application of D-AP5 was performed 60 min before stimulation (and 30 min before CHPG application). Control animals received vehicle injections at the same time points at which drug injections were given in their counterparts.

Data analysis. For each time point, five consecutively evoked responses at $40 \mathrm{~s}$ intervals were averaged. The first $30 \mathrm{~min}$ of recording (six time points) served as baseline and the results were expressed as a mean percentage \pm SEM of the average baseline value. Recordings were made every 5 min until 30 min after LFS/HFS and then every 15 min until $4 \mathrm{~h}$ had elapsed. The following day, an additional $1 \mathrm{~h}$ of recordings was obtained. For analysis of difference between groups, ANOVA with repeated measures was applied. If the ANOVA revealed a significant difference, interaction effects between time and group were assessed. The level of significance was set at $p<0.05$.

\section{Results}

mGlu5 antagonist MPEP has no effect on basal synaptic transmission

To evaluate whether MPEP has an influence on potentials evoked by test pulses, fEPSPs were monitored after application of MPEP at AC-CA3 and MF-CA3 synapses. At both synapses, MPEP does not alter basal synaptic transmission in the concentration used in this study (ANOVA, $F_{(1,3)}=0.0004, p=0.99$; interaction effect:
$F_{(34,102)}=0.61, p=0.95 ; n=4$; Fig. $2 A 1, A 2$ for MF-CA3 animals and ANOVA, $F_{(1,6)}=0.22, p=0.65$ interaction effect: $\mathrm{F}_{(34,204)}=$ $0.87, p=0.68 ; n=5$ for AC-CA3 animals; Fig. $2 B 1, B 2)$.

\section{Antagonism of mGlu5 prevents LTP at MF-CA3 synapses but} has no effect on LTP at AC synapses

HFS with 4 pulses of $100 \mathrm{~Hz}$ resulted in an LTP in vehicle-injected animals. Injection of the mGlu5 receptor antagonist MPEP $(1.8$ $\mu \mathrm{g}$ ) inhibited LTP at MF-CA3 synapses (ANOVA, $F_{(1,5)}=6.75$, $p<0.05$; interaction effect: $F_{(22,110)}=0.5, p=0.972 ; n=5$; Fig. $3 A 1, A 2)$. A different picture emerges at AC-CA3 synapses. Here, MPEP $(1.8 \mu \mathrm{g})$ did not alter field potentials compared with vehicle-injected animals when injected before given HFS (ANOVA, $F_{(1,8)}=0.00059, p=0.98$; interaction effect: $F_{(22,176)}=$ $0.54, p=0.95 ; n=5$; Fig. $3 B 1, B 2)$.

\section{Antagonism of mGlu5 prevents LTD at AC-CA3 synapses but} has no effect on LTD at MF synapses

LFS with 900 pulses at $1 \mathrm{~Hz}$ was applied to MF-CA3 and AC-CA3 synapses. In vehicle-injected animals, LFS resulted in LTD. Application of MPEP had no significant effect on the evoked potentials at MF-CA3 synapses (ANOVA, $F_{(1,4)}=1.23, p=0.33$; interaction effect: $F_{(22,88)}=1.1, p=0.37 ; n=3$; Fig. 3C1,C2). However, different from the effect seen at MF-CA3 synapses, MPEP impaired LTD at AC-CA3 synapses compared with vehicle-injected animals (ANOVA, $F_{(1,5)}=11.67, p<0.05$; interaction effect: $F_{(22,110)}=1.18$, $p=0.28 ; n=4$; Fig. 3D1,D2). To determine whether the residual depression that was evident when LFS was given in the presence of MPEP resulted from activation of NMDAR, we treated animals with D-AP5 30 min before MPEP application. A further 30 minutes later, we applied LFS. LTD was completely prevented and the impairment was significantly stronger than that seen when MPEP had been given alone (ANOVA, $F_{(1,10)}=6.09, p<0.05$; interaction effect: $F_{(22,220)}$ $=0.61, p=0.91 ; n=8$; Fig. $3 D 1, D 2)$. 

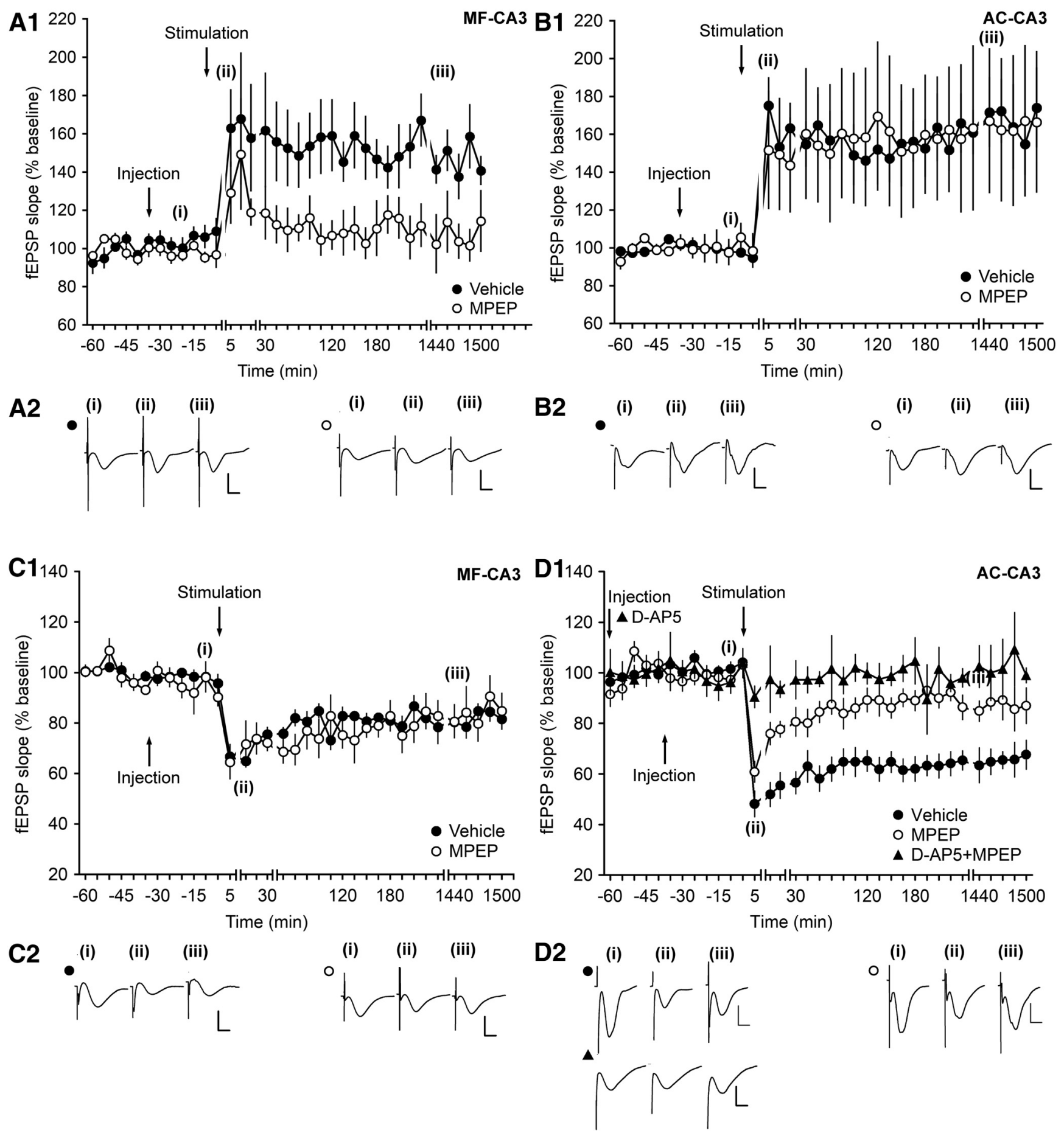

Figure 3. Antagonism of mGlu5 elicits highly selective effects on persistent forms of synaptic plasticity at MF-CA3 and AC-CA3 synapses. A1, HFS ( 4 trains of $100 \mathrm{pulses}$ at $100 \mathrm{~Hz}$ ) of MF-CA3 synapses, elicits LTP ( $>24 \mathrm{~h}$ ) in vehicle-injected animals. Intracerebral application of the mGlu5 antagonist MPEP (1.8 $\mu \mathrm{g})$ before HFS significantly blocks LTP. Line breaks indicate change in time scale. B1, In AC-CA3 synapses, HFS in the presence of vehicle results in LTP ( $>24 \mathrm{~h}$ ). MPEP treatment has no significant effect on the profile of AC-CA3 LTP. A2, B2, Analogs represent fEPSPs evoked pre-HFS (i), 5 min after HFS (iii), and $24 \mathrm{~h}$ after HFS (iii) in MF-CA3 synapses of vehicle-treated (filled circles) or MPEP-treated animals (open circles) (A2) and in AC-CA3 synapses of vehicle-treated (filled circles) or MPEP-treated animals (open circles) (B2). Vertical scale bar, $2 \mathrm{mV}$; horizontal scale bar, $8 \mathrm{~ms}$. (1, In MF-CA3 synapses, LFS ( $1 \mathrm{~Hz}, 900$ pulses) results in LTD in control animals. Intracerebral application of the mGlu5 antagonist MPEP (1.8 $\mu \mathrm{g}$ ) has no significant effect on LTD ( $>24 \mathrm{~h}$ ). Line breaks indicate change of time scale. D1, In AC-CA3 synapses, LFS results in LTD in control animals that lasts $>24 \mathrm{~h}$. Injection of MPEP before LFS significantly impairs LTD. Application of the NMDAR antagonist D-AP5 $(3.9 \mu \mathrm{g})$ before MPEP results in a significant further impairment of evoked responses. Line breaks indicate change of time scale. (2, D2, Analogs represent fEPSPs evoked pre-LFS (i), 5 min after LFS (ii), and $24 \mathrm{~h}$ after LFS (iii) in MF-CA3 synapses of vehicle-treated (filled circles) or MPEP-treated animals (open circles) (C2) and in AC-CA3 synapses of vehicle-treated (filled circles) or MPEP-treated animals (open circles) (D2). Vertical scale bar, $2 \mathrm{mV}$; horizontal scale bar, $8 \mathrm{~ms}$. 

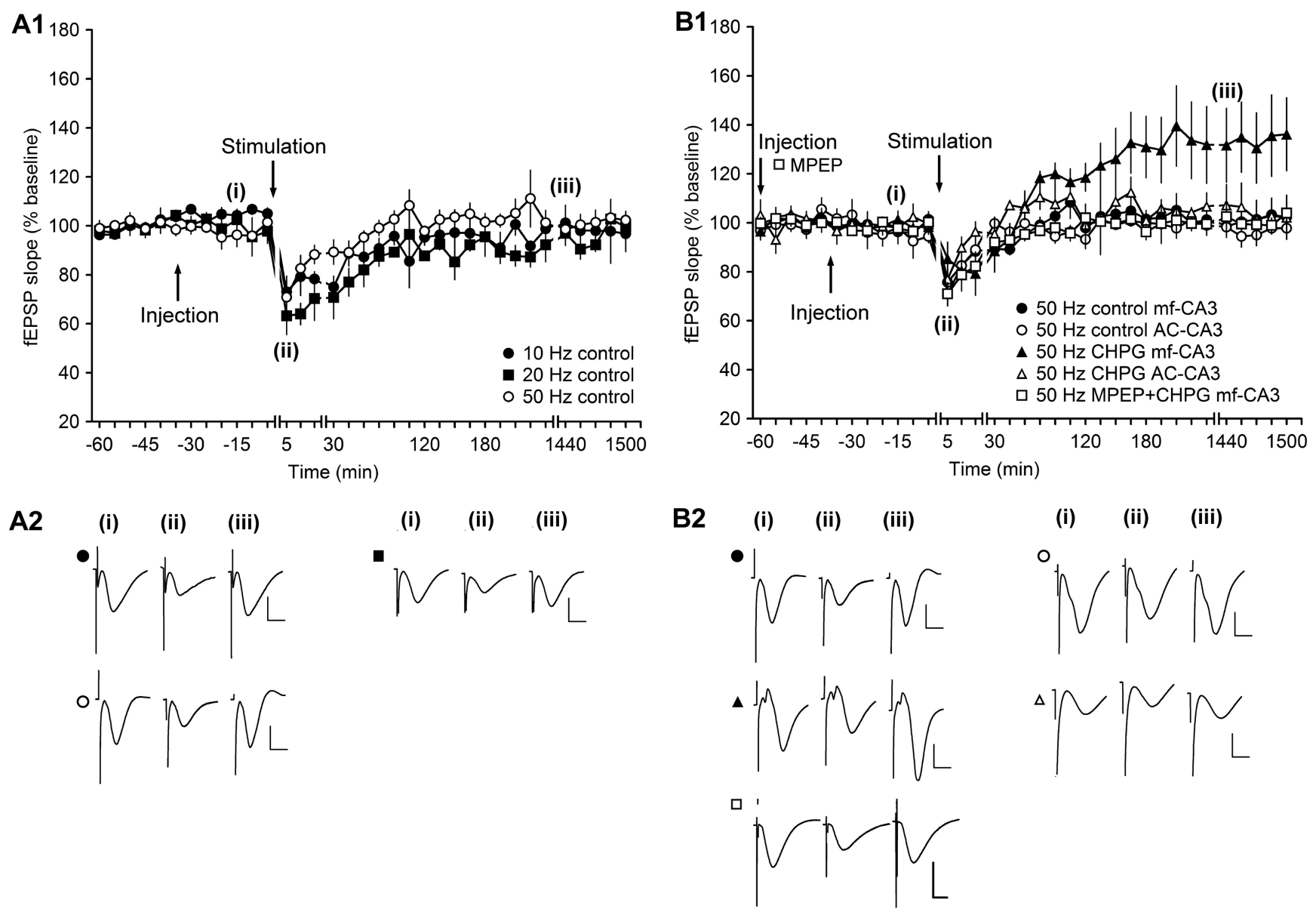

Figure 4. Activation of $\mathrm{mGlu5}$ receptors before afferent stimulation in the range of $\theta_{\mathrm{m}}$ potentiates evoked responses at MF-CA3 synapses but not at AC-CA3 synapses. $A 1$, In MF-CA3 synapses, stimulation at 10 or $20 \mathrm{~Hz}$ results in short-term depression (STD). Stimulation at $50 \mathrm{~Hz}$ leads to transient STD that is significantly smaller compared with STD evoked by $20 \mathrm{~Hz}$. Line breaks indicate change in time scale. $\mathbf{B 1}$, Stimulation at $50 \mathrm{~Hz}$ results in an equivalent transient depression of evoked responses in MF-CA3 and AC-CA3 synapses of vehicle-treated animals. Intracerebral application of the mGlu5 agonist CHPG $(0.5 \mu \mathrm{g})$ before $50 \mathrm{~Hz}$ stimulation results in synaptic potentiation in MF-CA3 synapses but not in AC-CA3 synapses. Application of MPEP before CHPG results in a prevention of the potentiation of evoked responses (in MF synapses) compared with effects seen in the presence of CHPG application alone. A2, Analogs represent fEPSPs evoked from MF-CA3 synapses before stimulation (i), 5 min after stimulation (ii), and $24 \mathrm{~h}$ after stimulation from animals that received $10 \mathrm{~Hz}$ (filled circles), $20 \mathrm{~Hz}$ (filled rectangles), or $50 \mathrm{~Hz}$ stimulation (open circles) (iii). Vertical scale bar, $2 \mathrm{mV}$; horizontal scale bar, $8 \mathrm{~ms}$. B2, Analogs represent fEPSPs evoked before $50 \mathrm{~Hz}$ (i), $5 \mathrm{~min}$ after $50 \mathrm{~Hz}$ (ii), and $24 \mathrm{~h}$ after $50 \mathrm{~Hz}$ (iii). Upper left traces depict fEPSPs recorded from MF-CA3 synapses of control animals (filled circles) and lower left traces show responses in the presence of CHPG (filled triangles). Upper right traces depict fEPSPs recorded from AC-CA3 synapses of control animals (open circles) and lower right traces show responses in AC-CA3 synapses in the presence of CHPG (open triangles). Vertical scale bar, $2 \mathrm{mV}$; horizontal scale bar, $8 \mathrm{~ms}$.

Agonist activation of mGlu5 results in synaptic potentiation at MF but not AC synapses following afferent stimulation in the range of $\theta_{\mathrm{m}}$

The strikingly opposing results seen at the MF and AC synapses in response to antagonism of mGlu5 raised the question as to whether, under ambivalent conditions, it can preferentially influence the direction of experience-dependent triggered changes of synaptic strength. By "ambivalent," we mean the physiological situation first proposed by Bienenstock et al. (1982) and later confirmed empirically by different scientists (Artola and Singer, 1993; Abraham et al., 2001; Kemp and Manahan-Vaughan, 2005; Zhang et al., 2005) in which certain afferent frequencies cause substantial postsynaptic activity that is not overtly detectable as a change in synaptic strength. These frequencies are in the range of $10-50 \mathrm{~Hz}$. They are too fast to elicit LTD and too slow to elicit LTP. The postsynaptic activity that occurs at these frequencies is believed to comprise a competition between LTP-inducing factors and LTD-inducing factors (Stanton, 1996) that cancel each other out. This crossover point between LTD and LTP is referred to as $\theta_{\mathrm{m}}$ (Bienenstock et al., 1982; Wexler and Stanton, 1993; Stanton, 1996). We investigated whether activating mGlu5 at $\theta_{\mathrm{m}}$ frequencies would push postsynaptic activity to favor LTP, consistent with our interpretation of the abovementioned plasticity results. First, we assessed effects of 10, 20, and $50 \mathrm{~Hz}$ stimulation on synaptic strength at MF synapses. Stimulation with 450 pulses at $10 \mathrm{~Hz}$ resulted in a transient short-term depression that lasted for $\sim 2 \mathrm{~h}$ (ANOVA, $F_{(1,6)}=16.88, p<0.01$; interaction effect: $F_{(9,54)}=1.94, p=0.06 ; n=4$; Fig. $\left.4 A 1, A 2\right)$ compared with test-pulse stimulation. Stimulation with 450 pulses at $20 \mathrm{~Hz}$ also resulted in STD (ANOVA, $F_{(1,6)}=18.98, p<0.01$; interaction effect: $F_{(9,54)}=5.23, p<0.001 ; n=4$; Fig. $\left.4 A 1, A 2\right)$ compared with test-pulse stimulation that was not significantly different compared with STD elicited by $10 \mathrm{~Hz}$ stimulation (ANOVA, $F_{(1,6)}=1.17, p=0.32$; interaction effect: $F_{(22,132)}=0.75, p=$ $0.78 ; n=4$; Fig. $4 A 1, A 2)$. Stimulation with 450 pulses at $50 \mathrm{~Hz}$ elicited a very small and brief ( $<15 \mathrm{~min}$ ) depression that was significantly smaller than that seen with $20 \mathrm{~Hz}$ stimulation $\left(\right.$ ANOVA, $F_{(1,9)}=10.71, p<0.01$; interaction effect: $F_{(22,198)}=$ $0.86, p=0.65 ; n=7$; Fig. $4 A 1, A 2)$. We therefore used this protocol for testing with the mGlu5 agonist.

Stimulation of MF or AC synapses in the presence of vehicle resulted in an equivalent synaptic response in both synaptic pop- 
ulations (ANOVA, $F_{(1,9)}=0.34, p=0.05$; interaction effect: $F_{(22,198)}=0.93, p=0.56 ; n=7 ;$ Fig. $\left.4 B 1, B 2\right)$. Treatment with the selective mGlu5 agonist CHPG (20 ng) $30 \mathrm{~min}$ before $50 \mathrm{~Hz}$ stimulation of MF-CA3 synapses resulted in a synaptic potentiation of evoked responses (ANOVA, $F_{(1,3)}=11.47, p<0.05$; interaction effect: $F_{(22,88)}=3.41, p<0.001 ; n=4$; Fig. 4B1,B2). In contrast, in the presence of CHPG (20 ng), $50 \mathrm{~Hz}$ stimulation evoked synaptic responses at AC synapses that were equivalent to vehicle-treated controls responses (ANOVA, $F_{(1,6)}=2.5, p=$ 0.17 ; interaction effect: $F_{(22,132)}=0.56, p=0.94 ; n=4$; Fig. $4 B 1, B 2$ ). Bortolotto et al. (2008) reported that very few stimuli are sufficient to activate mGlu5 receptors in CA1 and Charpak and Gahwiler (1991) reported that a single stimulus burst activated group I mGlu receptors at MF synapses. To verify that the effects we observed were mediated by mGlu5, we conducted an additional experiment in which MPEP was given $30 \mathrm{~min}$ before application of CHPG. A further 30 in later, $50 \mathrm{~Hz}$ stimulation was applied. This resulted in a significant inhibition of responses compared with application of CHPG alone (ANOVA, $F_{(1,9)}=$ $5.29, p<0.05$; interaction effect: $F_{(19,171)}=1.22, p=0.25 ; n=4$; Fig. $4 B 1, B 2)$. Together, these data suggest that, when information at $\theta_{\mathrm{m}}$ frequencies reaches the CA3 region and the postsynaptic response is strong enough to activate mGlu5, information processing in the form of synaptic potentiation is favored at MF synapses.

\section{Discussion}

This study demonstrates how certain forms of information processing can be prioritized at MF versus AC synapses such that optimized information processing and/or storage can occur. Specifically, mGlu5 acts as a toggle switch that determines the direction of change in synaptic strength at these synapses. These findings suggest that fundamentally different information storage mechanisms are favored at the MF and AC synapses that in turn may underlie the unique role of the $\mathrm{CA} 3$ region in information processing.

The CA3 region contributes to working memory and pattern completion (Marr, 1971; Nakazawa et al., 2002; Kesner, 2007; Leutgeb and Leutgeb, 2007; Neunuebel and Knierim, 2014) and the MF synapses may enable these functions (Nakazawa et al., 2002; Bischofberger et al., 2006; Kesner and Warthen, 2010; Hagena and Manahan-Vaughan, 2011; Nakashiba et al., 2012; Neunuebel and Knierim, 2014). MF synapses are unique in their ability to respond to LFS with spectacular increases in the size of evoked potentials (Salin et al., 1996; Toth et al., 2000; Moore et al., 2003; Nicoll and Schmitz, 2005; Klausnitzer and ManahanVaughan, 2008, 2010). This phenomenon, known as frequency facilitation (Salin et al., 1996), lasts in vitro for as long as the afferent stimulation occurs (Moore et al., 2003) and we postulate that it corresponds to the holding of information "online" that occurs while information is being used and sorted. This could be required for the completion of an acute spatial task or for pattern completion (Hagena and Manahan-Vaughan, 2010). In vivo, prolonged periods of frequency facilitation are succeeded by LTD (Hagena and Manahan-Vaughan, 2010). LTD accompanies the acquisition of knowledge about new spatial content or positional attributes (Manahan-Vaughan and Braunewell, 1999; Kemp and Manahan-Vaughan, 2004, 2008; Hagena and ManahanVaughan, 2011; Goh and Manahan-Vaughan, 2013b). Therefore, it is possible that the segueing of frequency facilitation into LTD at MF synapses relates to the process of converting working memory into a more resilient and lasting engram.

LTP in the CA3 and other hippocampal subfields is tightly associated with the acquisition of novel information about spatial scenes, space, or environmental change (Straube et al., 2003;
Kemp and Manahan-Vaughan, 2004; Hagena and ManahanVaughan, 2011; Kenney and Manahan-Vaughan, 2013). In the context of information processing at MF synapses, this process may also correspond to the generation and reactivation of synaptic networks related to pattern completion. The MF synapses also express LTD in association with novel learning about the position of navigational or orientational, features of a spatial environment (Hagena and Manahan-Vaughan, 2011). The significance of long-lasting synaptic plasticity in AC synapses is less clear. Conversely, learning about subtle aspects of spatial content facilitates AC-LTD (Hagena and Manahan-Vaughan, 2011), suggesting that this synapse also plays a distinct role in encoding specific aspects of a spatial representation. On the other hand, the recurrent projections of the $\mathrm{AC}$ fibers give rise to massive excitation of CA3 pyramidal cells (Bains et al., 1999; Bischofberger et al., 2006) that could serve to reinforce information encoding in MF synapses. This kind of input could also give rise to substantial "noise" that renders information encoding in the $\mathrm{CA} 3$ region less specific.

Strikingly, we observed that a mechanism is in place in the CA3 region that can address this very confound. MGlu5 appears to function as a switch that drives information encoding in the MF synapses via synaptic potentiation while promoting synaptic depression in AC synapses. Receptor-antagonism revealed that opposing but highly complementary forms of synaptic plasticity are mediated at MF and AC synapses by mGlu5. LTP requires mGlu5 activation at MF synapses and LTD requires mGlu5 activation at AC synapses. Furthermore, when incoming afferent information is of a frequency that is too fast to induce LTD but too slow to induce LTP, activation of mGlu5 results in the direction of change of synaptic weights moving toward potentiation.

MGlu5 is not expressed in the postsynaptic density, rather, it is expressed extrasynaptically (Lujan et al., 1996). Consistent with this, antagonists of mGlu5 do not affect basal synaptic tonus (Naie and Manahan-Vaughan, 2004; Manahan-Vaughan and Braunewell, 2005; Goh and Manahan-Vaughan, 2013a), as was also the case in MF and AC synapses in the present study. Antagonism of mGlu5 prevents both LTP and LTD in the CA1 region and dentate gyrus (Naie and Manahan-Vaughan, 2004; Neyman and Manahan-Vaughan, 2008; Popkirov and Manahan-Vaughan, 2011), suggesting that, under conditions of contiguous glutamate release into the synaptic cleft, glutamate spillover reaches extrasynaptic mGlu5 and contributes to the intracellular processes that result in the prolonged maintenance of synaptic plasticity. These processes relate to hippocampus-dependent working and reference memory (Naie and Manahan-Vaughan, 2004).

In contrast to MF synapses, synaptic plasticity at AC synapses is NMDAR dependent (Harris and Cotman, 1986; Zalutsky and Nicoll, 1990; Debanne et al., 1998; Selig et al., 1999; Nakazawa et al., 2002). So far, few studies have focused on the involvement of group I mGlu receptors in AC-LTP (Kobayashi and Poo, 2004; Yang et al., 2013) and none of them examined mGlu5 receptors in vivo. In contrast to CA1 synapses, where NMDAR-LTP requires activation of mGlu5 to persist for periods of hours and days (Popkirov and Manahan-Vaughan, 2011), in AC synapses in vivo, LTP is unaffected by antagonism of mGlu5 receptors. Conversely, mGlu5 antagonism results in inhibition of AC-LTD in vivo. This effect could be due to changes in intracellular calcium levels caused by inhibition of NMDAR currents, which are modulated by mGlu5 (Mannaioni et al., 2001; Harney et al., 2006).

How can mGlu5 exert such a differentiated control of LTP at MF and of LTD at AC synapses? One possibility is that the relative distribution and expression of mGlu5 is distinct at these synapses. Another possibility is that high-frequency information in- 
put, as was used to trigger LTP in the present study, has a more potent effect on membrane depolarization, glutamate release, and the recruitment of auxiliary aspects such as voltage-gated calcium channels at AC synapses compared with MF synapses due to the recurrent network and its amplification effects on postsynaptic excitability (Harris and Cotman, 1986; Miles and Wong, 1986; de Almeida et al., 2007; for review, see Le Duigou et al., 2014). These may "bypass" the need for mGlu5 activation to trigger intracellular mechanisms that support LTP. In contrast, under conditions in which LTD-inducing (low-frequency) afferent stimulation occurs, it is possible that glutamate spillover at MF synapses is inadequate to activate MF synapses, whereby LTD is supported by processes such as $\mathrm{Ca}^{2+}$-influx mediated by L-type $\mathrm{Ca}^{2+}$-channels that follows membrane depolarization via NMDAR (Hunt et al., 2013). In AC synapses, the excitability of the recurrent network is sufficient to cause adequate glutamate spillover to activate mGlu5 and recruit this receptor into LTD maintenance processes. MF-LTP may be prioritized, however, as afferent stimulation that lies at the crossover point between LTD and LTP $\left(\theta_{\mathrm{m}}\right.$; Bienenstock et al., 1982; Stanton, 1996), resulting in mGlu5 activation that facilitates synaptic potentiation at MF synapses without affecting the transient depression that is elicited at AC synapses.

Our data have interesting functional implications. MFs form synapses near the soma of CA3 pyramidal cells and strongly influence $\mathrm{CA} 3$ cell function. AC fibers synapse preferentially at the proximal parts of the dendrites of CA3 cells (Claiborne et al., 1993). A promotion of LTP processes at MF synapses that is concurrent with the promotion of LTD processes at AC synapses could be expected to result in very specific encoding of synaptic information close to the soma. If this resulted in the encoding of a specific spatial representation (a pattern, so to speak), then the subsequent transmission of a fragment of this experience to this network could be expected to result in a ready activation of the established network: pattern completion, in other words.

The AC network plays a distinct role in spatial information encoding that should not be ignored. Novel learning about discrete spatial or positional features facilitates LTD at AC synapses, whereas navigational-related spatial content facilitates LTD at MF synapses (Hagena and Manahan-Vaughan, 2011). This suggests that both synapses contribute to the generation of complex spatial representations by the hippocampus. From this point of view, the dependency of AC-LTD and MF-LTP on mGlu5 suggests that this receptor may serve as a means whereby selective information processing of specific aspects of spatial content occurs in CA3 pyramidal cells.

\section{Conclusion}

Our findings offer new insight into the mechanisms that support CA3-dependent information processing phenomena. The anatomical location of mGlu5 (Lujan et al., 1996; Cosgrove et al., 2011) and its lack of contribution to basal synaptic transmission suggest that this receptor is only active during conditions of intense presynaptic and postsynaptic activity. On a functional level, this can be expected to occur under conditions of highly salient behavioral, presumably spatial, experience. This may occur during novel learning or during events in which the hippocampus is required to determine whether a spatial experience that appears similar to a past experience is novel (pattern separation) or familiar (pattern completion), whereby the latter phenomenon is believed to be predominantly CA3 dependent (Nakashiba et al., 2012; Neunuebel and Knierim, 2014). Under these circumstances, the intensity of afferent input to the CA3 region results in mGlu5 activation that preferentially supports LTP expression at MF synapses and LTD at AC synapses. This kind of bidirectional regulation of synaptic strength can be expected to drive information storage at MF synapses on the background of an optimized signal-to-noise ratio within the pyramidal neuron. This process may subserve novel pattern encoding or facilitate pattern completion related to scene memory at MF synapses. Conversely, the same optimized signal-to-noise ratio may support the encoding of spatial content at AC synapses (Hagena and Manahan-Vaughan, 2011) such that the MF and AC synaptic network contribute distinct and different aspects of a complex spatial representation.

\section{References}

Abraham WC, Mason-Parker SE, Bear MF, Webb S, Tate WP (2001) Heterosynaptic metaplasticity in the hippocampus in vivo: a BCM-like modifiable threshold for LTP. Proc Natl Acad Sci U S A 98:10924-10929. CrossRef Medline

Amaral DG (1979) Synaptic extensions from the mossy fibers of the fascia dentata. Anat Embryol 155:241-251. CrossRef Medline

Artola A, Singer W (1993) Long-term depression of excitatory synaptic transmission and its relationship to long-term potentiation. Trends Neurosci 16:480-487. CrossRef Medline

Bains JS, Longacher JM, Staley KJ (1999) Reciprocal interactions between CA3 network activity and strength of recurrent collateral synapses. Nat Neurosci 2:720-726. CrossRef Medline

Bienenstock EL, Cooper LN, Munro PW (1982) Theory for the development of neuron selectivity: orientation specificity and binocular interaction in visual cortex. J Neurosci 2:32-48. Medline

Bikbaev A, Neyman S, Ngomba RT, Conn PJ, Conn J, Nicoletti F, ManahanVaughan D (2008) MGluR5 mediates the interaction between late-LTP, network activity, and learning. PLoS One 3:e2155. CrossRef Medline

Bischofberger J, Engel D, Frotscher M, Jonas P (2006) Timing and efficacy of transmitter release at mossy fiber synapses in the hippocampal network. Pflugers Arch 453:361-372. CrossRef Medline

Blackstad TW (1956) Commissural connections of the hippocampal region in the rat, with special reference to their mode of termination. J Comp Neurol 105:417-537. CrossRef Medline

Blackstad TW, Brink K, Hem J, Jeune B (1970) Distribution of hippocampal mossy fibers in the rat: an experimental study with silver impregnation methods. J Comp Neurol 138:433-449. CrossRef Medline

Bock P (1989) Romeis Mikroskopische Technik. München: Urban \& Schwarzenberg.

Bortolotto ZA, Collett VJ, Conquet F, Jia Z, Collingridge GL (2008) An analysis of the stimulus requirements for setting the molecular switch reveals a lower threshold for metaplasticity than synaptic plasticity. Neuropharmacology 55:454-458. CrossRef Medline

Charpak S, Gähwiler BH (1991) Glutamate mediates a slow synaptic response in hippocampal slice cultures. Proc Biol Sci 243:221-226. CrossRef Medline

Claiborne BJ, Xiang Z, Brown TH (1993) Hippocampal circuitry complicates analysis of long-term potentiation in mossy fiber synapses. Hippocampus 3:115-121. CrossRef Medline

Cosgrove KE, Galván EJ, Barrionuevo G, Meriney SD (2011) mGluRs modulate strength and timing of excitatory transmission in hippocampal area CA3. Mol Neurobiol 44:93-101. CrossRef Medline

de Almeida L, Idiart M, Lisman JE (2007) Memory retrieval time and memory capacity of the CA3 network: role of gamma frequency oscillations. Learn Mem 14:795-806. CrossRef Medline

Debanne D, Gähwiler BH, Thompson SM (1998) Long-term synaptic plasticity between pairs of individual CA3 pyramidal cells in rat hippocampal slice cultures. J Physiol 507:237-247. CrossRef Medline

Dudek SM, Bear MF (1993) Bidirectional long-term modification of synaptic effectiveness in the adult and immature hippocampus. J Neurosci 13:2910-2918. Medline

Gasparini F, Lingenhöhl K, Stoehr N, Flor PJ, Heinrich M, Vranesic I, Biollaz M, Allgeier H, Heckendorn R, Urwyler S, Varney MA, Johnson EC, Hess SD, Rao SP, Sacaan AI, Santori EM, Veliçelebi G, Kuhn R (1999) 2-Methyl-6-(phenylethynyl)-pyridine (MPEP), a potent, selective and systemically active mGlu5 receptor antagonist. Neuropharmacology 38:1493-1503. CrossRef Medline

Goh JJ, Manahan-Vaughan D (2013a) Endogenous hippocampal LTD that is enabled by spatial object recognition requires activation of NMDA receptors and the metabotropic glutamate receptor, mGlu5. Hippocampus 23:129-138. Medline

Goh JJ, Manahan-Vaughan D (2013b) Spatial object recognition enables endogenous LTD that curtails LTP in the mouse hippocampus. Cereb Cortex 23:1118-1125. Medline 
Goh JJ, Manahan-Vaughan D (2013c) Synaptic depression in the CA1 region of freely behaving mice is highly dependent on afferent stimulation parameters. Front Integr Neurosci 7:1. Medline

Hagena H, Manahan-Vaughan D (2010) Frequency facilitation at mossy fiber-CA3 synapses of freely behaving rats contributes to the induction of persistent LTD via an adenosine-A1 receptor-regulated mechanism. Cereb Cortex 20:1121-1130. CrossRef Medline

Hagena H, Manahan-Vaughan D (2011) Learning-facilitated synaptic plasticity at CA3 mossy fiber and commissural-associational synapses reveals different roles in information processing. Cereb Cortex 21:2442-2449. CrossRef Medline

Harney SC, Rowan M, Anwyl R (2006) Long-term depression of NMDA receptormediated synaptic transmission is dependent on activation of metabotropic glutamate receptors and is altered to long-term potentiation by low intracellular calcium buffering. J Neurosci 26:1128-1132. CrossRef Medline

Harris EW, Cotman CW (1986) Long-term potentiation of guinea pig mossy fiber responses is not blocked by $\mathrm{N}$-methyl $\mathrm{D}$-aspartate antagonists. Neurosci Lett 70:132-137. CrossRef Medline

Hunt DL, Puente N, Grandes P, Castillo PE (2013) Bidirectional NMDA receptor plasticity controls CA3 output and heterosynaptic metaplasticity. Nat Neurosci 16:1049-1059. CrossRef Medline

Kamiya H, Shinozaki H, Yamamoto C (1996) Activation of metabotropic glutamate receptor type $2 / 3$ suppresses transmission at rat hippocampal mossy fibre synapses. J Physiol 493:447-455. CrossRef Medline

Kemp A, Manahan-Vaughan D (2004) Hippocampal long-term depression and long-term potentiation encode different aspects of novelty acquisition. Proc Natl Acad Sci U S A 101:8192-8197. CrossRef Medline

Kemp A, Manahan-Vaughan D (2005) The 5-hydroxytryptamine4 receptor exhibits frequency-dependent properties in synaptic plasticity and behavioural metaplasticity in the hippocampal CA1 region in vivo. Cereb Cortex 15:1037-1043. Medline

Kemp A, Manahan-Vaughan D (2007) Hippocampal long-term depression: master or minion in declarative memory processes? Trends Neurosci 30: 111-118. CrossRef Medline

Kemp A, Manahan-Vaughan D (2008) The hippocampal CA1 region and dentate gyrus differentiate between environmental and spatial feature encoding through long-term depression. Cereb Cortex 18:968-977. CrossRef Medline

Kenney J, Manahan-Vaughan D (2013) Learning-facilitated synaptic plasticity occurs in the intermediate hippocampus in association with spatial learning. Front Synaptic Neurosci 5:10. Medline

Kesner RP (2007) Behavioral functions of the CA3 subregion of the hippocampus. Learn Mem 14:771-781. CrossRef Medline

Kesner RP, Warthen DK (2010) Implications of CA3 NMDA and opiate receptors for spatial pattern completion in rats. Hippocampus 20:550-557. Medline

Klausnitzer J, Manahan-Vaughan D (2008) Frequency facilitation at mossy fiber-CA3 synapses of freely behaving rats is regulated by adenosine A1 receptors. J Neurosci 28:4836-4840. CrossRef Medline

Kobayashi K, Poo MM (2004) Spike train timing-dependent associative modification of hippocampal CA3 recurrent synapses by mossy fibers. Neuron 41:445-454. CrossRef Medline

Le Duigou C, Simonnet J, Teleñczuk MT, Fricker D, Miles R (2014) Recurrent synapses and circuits in the $\mathrm{CA} 3$ region of the hippocampus: an associative network. Front Cell Neurosci 7:262. Medline

Leutgeb S, Leutgeb JK (2007) Pattern separation, pattern completion, and new neuronal codes within a continuous CA3 map. Learn Mem 14:745757. CrossRef Medline

Lujan R, Nusser Z, Roberts JD, Shigemoto R, Somogyi P (1996) Perisynaptic location of metabotropic glutamate receptors mGluR1 and mGluR5 on dendrites and dendritic spines in the rat hippocampus. Eur J Neurosci 8:1488-1500. CrossRef Medline

Manahan-Vaughan D (1997) Group 1 and 2 metabotropic glutamate receptors play differential roles in hippocampal long-term depression and long-term potentiation in freely moving rats. J Neurosci 17:3303-3311. Medline

Manahan-Vaughan D, Braunewell KH (1999) Novelty acquisition is associated with induction of hippocampal long-term depression. Proc Natl Acad Sci U S A 96:8739-8744. CrossRef Medline

Manahan-Vaughan D, Braunewell KH (2005) The metabotropic glutamate receptor, mGluR5, is a key determinant of good and bad spatial learning performance and hippocampal synaptic plasticity. Cereb Cortex 15:17031713. CrossRef Medline

Manahan-Vaughan D, Reymann KG, Brown RE (1998) In vivo electrophysiological investigations into the role of histamine in the dentate gyrus of the rat. Neuroscience 84:783-790. CrossRef Medline
Mannaioni G, Marino MJ, Valenti O, Traynelis SF, Conn PJ (2001) Metabotropic glutamate receptors 1 and 5 differentially regulate CA1 pyramidal cell function. J Neurosci 21:5925-5934. Medline

Marr D (1971) Simple memory: a theory for archicortex. Philos Trans R Soc Lond B Biol Sci 262:23-81. CrossRef Medline

Miles R, Wong RK (1986) Excitatory synaptic interactions between CA3 neurones in the guinea-pig hippocampus. J Physiol 373:397-418. CrossRef Medline

Moore KA, Nicoll RA, Schmitz D (2003) Adenosine gates synaptic plasticity at hippocampal mossy fiber synapses. Proc Natl Acad Sci U S A 100: 14397-14402. CrossRef Medline

Mukherjee S, Manahan-Vaughan D (2013) Role of metabotropic glutamate receptors in persistent forms of hippocampal plasticity and learning. Neuropharmacology 66:65-81. Medline

Naie K, Manahan-Vaughan D (2004) Regulation by metabotropic glutamate receptor 5 of LTP in the dentate gyrus of freely moving rats: relevance for learning and memory formation. Cereb Cortex 14:189-198. CrossRef Medline

Naie K, Tsanov M, Manahan-Vaughan D (2007) Group I metabotropic glutamate receptors enable two distinct forms of long-term depression in the rat dentate gyrus in vivo. Eur J Neurosci 25:3264-3275. CrossRef Medline

Nakashiba T, Cushman JD, Pelkey KA, Renaudineau S, Buhl DL, McHugh TJ, Rodriguez Barrera V, Chittajallu R, Iwamoto KS, McBain CJ, Fanselow MS, Tonegawa S (2012) Young dentate granule cells mediate pattern separation, whereas old granule cells facilitate pattern completion. Cell 149:188-201. CrossRef Medline

Nakazawa K, Quirk MC, Chitwood RA, Watanabe M, Yeckel MF, Sun LD, Kato A, Carr CA, Johnston D, Wilson MA, Tonegawa S (2002) Requirement for hippocampal CA3 NMDA receptors in associative memory recall. Science 297:211-218. CrossRef Medline

Neunuebel JP, Knierim JJ (2014) CA3 retrieves coherent representations from degraded input: direct evidence for CA3 pattern completion and dentate gyrus pattern separation. Neuron 81:416-427. CrossRef Medline

Neyman S, Manahan-Vaughan D (2008) Metabotropic glutamate receptor 1 (mGluR1) and 5 (mGluR5) regulate late phases of LTP and LTD in the hippocampal CA1 region in vitro. Eur J Neurosci 27:1345-1352. CrossRef Medline

Nicoll RA, Schmitz D (2005) Synaptic plasticity at hippocampal mossy fibre synapses. Nat Rev Neurosci 6:863-876. CrossRef Medline

Popkirov SG, Manahan-Vaughan D (2011) Involvement of the metabotropic glutamate receptor mGluR5 in NMDA receptor-dependent, learning-facilitated long-term depression in CA1 synapses. Cereb Cortex 21:501-509. CrossRef Medline

Salin PA, Scanziani M, Malenka RC, Nicoll RA (1996) Distinct short-term plasticity at two excitatory synapses in the hippocampus. Proc Natl Acad Sci U S A 93:13304-13309. CrossRef Medline

Selig DK, Nicoll RA, Malenka RC (1999) Hippocampal long-term potentiation preserves the fidelity of postsynaptic responses to presynaptic bursts. J Neurosci 19:1236-1246. Medline

Stanton PK (1996) LTD, LTP, and the sliding threshold for long-term synaptic plasticity. Hippocampus 6:35-42. Medline

Straube T, Korz V, Frey JU (2003) Bidirectional modulation of long-term potentiation by novelty-exploration in rat dentate gyrus. Neurosci Lett 344:5-8. CrossRef Medline

Toth K, Suares G, Lawrence JJ, Philips-Tansey E, McBain CJ (2000) Differential mechanisms of transmission at three types of mossy fiber synapse. J Neurosci 20:8279-8289. Medline

Wexler EM, Stanton PK (1993) Priming of homosynaptic long-term depression in hippocampus by previous synaptic activity. Neuroreport 4:591-594. CrossRef Medline

Yang S, Megill A, Ardiles AO, Ransom S, Tran T, Koh MT, Lee HK, Gallagher M, Kirkwood A (2013) Integrity of mGluR-LTD in the associative/commissural inputs to CA3 correlates with successful aging in rats. J Neurosci 33:12670-12678. CrossRef Medline

Yeckel MF, Kapur A, Johnston D (1999) Multiple forms of LTP in hippocampal CA3 neurons use a common postsynaptic mechanism. Nat Neurosci 2:625-633. CrossRef Medline

Zalutsky RA, Nicoll RA (1990) Comparison of two forms of long-term potentiation in single hippocampal neurons. Science 248:1619-1624. CrossRef Medline

Zhang L, Kirschstein T, Sommersberg B, Merkens M, Manahan-Vaughan D, Elgersma Y, Beck H (2005) Hippocampal synaptic metaplasticity requires inhibitory autophosphorylation of $\mathrm{Ca} 2+/$ calmodulin-dependent kinase II. J Neurosci 25:7697-7707. CrossRef Medline 